\title{
The Long-Term Conditions Questionnaire: conceptual framework and item development
}

This article was published in the following Dove Press journal:

Patient Related Outcome Measures

30 August 2016

Number of times this article has been viewed

\section{Michele Peters' \\ Caroline M Potter' \\ Laura Kelly' \\ Cheryl Hunter' \\ Elizabeth Gibbons' \\ Crispin Jenkinson' \\ Angela Coulter' \\ Julien Forder ${ }^{2}$ \\ Ann-Marie Towers ${ }^{2}$ \\ Christine A'Court ${ }^{3,4}$ \\ Ray Fitzpatrick'}

'Health Services Research Unit, Nuffield Department of Population Health, University of Oxford, Oxford, ${ }^{2}$ Personal Social Services Research Unit, University of Kent, Canterbury, ${ }^{3}$ Nuffield Department of Primary Health Care Sciences, University of Oxford, Oxford, ${ }^{4}$ Broadshires Health Centre, Carterton, UK
Correspondence: Michele Peters Health Services Research Unit, Nuffield Department of Population Health, University of Oxford, Old Road Campus, Oxford OX3 7LF, UK

Telephone +44I865 289428

Email michele.peters@dph.ox.ac.uk
Purpose: To identify the main issues of importance when living with long-term conditions to refine a conceptual framework for informing the item development of a patient-reported outcome measure for long-term conditions.

Materials and methods: Semi-structured qualitative interviews $(n=48)$ were conducted with people living with at least one long-term condition. Participants were recruited through primary care. The interviews were transcribed verbatim and analyzed by thematic analysis. The analysis served to refine the conceptual framework, based on reviews of the literature and stakeholder consultations, for developing candidate items for a new measure for long-term conditions.

Results: Three main organizing concepts were identified: impact of long-term conditions, experience of services and support, and self-care. The findings helped to refine a conceptual framework, leading to the development of 23 items that represent issues of importance in longterm conditions. The 23 candidate items formed the first draft of the measure, currently named the Long-Term Conditions Questionnaire.

Conclusion: The aim of this study was to refine the conceptual framework and develop items for a patient-reported outcome measure for long-term conditions, including single and multiple morbidities and physical and mental health conditions. Qualitative interviews identified the key themes for assessing outcomes in long-term conditions, and these underpinned the development of the initial draft of the measure. These initial items will undergo cognitive testing to refine the items prior to further validation in a survey.

Keywords: long-term conditions, conceptual framework, qualitative interviews, patient-reported outcome measure

\section{Introduction}

Patient-reported outcome measures (PROMs) have been proposed as a means to measure what matters to patients to strengthen patient involvement in their care, to enable individualization of care, ${ }^{1}$ and to evaluate the performance and quality of care. ${ }^{2}$ It is generally agreed that a PROM should have a clear underlying conceptual framework, ${ }^{3-5}$ which specifies the specific goal of the measure, its intended use, and the target population. ${ }^{3,4}$ Although these criteria have been highlighted in particular for PROMs used in clinical trials, it is equally important that PROMs developed for use in other contexts, such as clinical practice or performance monitoring, are also developed to a high standard. It is recommended that an initial hypothesized conceptual framework be based on a literature review and expert opinion, and that this framework be further refined as domains and items are developed on the basis of in-depth qualitative and cognitive interviews. ${ }^{5}$ 
Table I Initial domains in the conceptual framework for the development of the Long-Term Conditions Questionnaire

\begin{tabular}{|c|c|}
\hline $\begin{array}{l}\text { Literature reviews of key } \\
\text { domains }\end{array}$ & Stakeholder interviews ${ }^{a}$ \\
\hline $\begin{array}{l}\text { 1. Outcomes included in generic } \\
\text { and disease-specific PROMs } \\
\text { 2. Self-management } \\
\text { 3. Coping } \\
\text { 4. Empowerment } \\
\text { 5. Burden of treatment } \\
\text { 6. Stigma } \\
\text { 7. Safety } \\
\text { 8. Involvement in decision making } \\
\text { 9. Information and health literacy } \\
\text { 10. Ability to achieve goals } \\
\text { 11. Social participation } \\
\text { 12. Social support }\end{array}$ & $\begin{array}{l}\text { I. Empowerment } \\
\text { 2. Quality of life or impact of } \\
\text { illness and/or treatment on life } \\
\text { 3. Patient-specific or personalized } \\
\text { goals } \\
\text { 4. Functioning (including social, } \\
\text { physical, and psychological) } \\
\text { 5. Social participation } \\
\text { 6. Psychological well-being } \\
\text { 7. Symptoms or clinical outcomes } \\
\text { 8. Access to services (includes } \\
\text { access to information) } \\
\text { 9. Joined-up nature of services } \\
\text { 10. Impact on carers }\end{array}$ \\
\hline
\end{tabular}

Notes: aAdapted from Hunter C, Fitzpatrick R, Jenkinson C, et al. Perspectives from health, social care and policy stakeholders on the value of a single self-report outcome measure across long-term conditions: a qualitative study. BMJ Open. 2015;5(5):e006986. ${ }^{18}$

Abbreviation: PROMs, patient-reported outcome measures.

Long-term chronic conditions are the main challenge facing health and social care services today, due to their increasing prevalence, complexity, and impact on quality of life. ${ }^{6-10}$ Multimorbidity adds further to this challenge. Enhancing quality of life for people with long-term conditions (LTCs) by monitoring PROM scores is a key goal of health and social care policy in England and in other countries. ${ }^{11-14}$ The use of PROMs has been pilot-tested for six LTCs in primary care. ${ }^{15}$ This pilot study highlighted a number of challenges, including the reporting of PROM data (for one generic and six disease-specific PROMs) in a meaningful and concise manner across multiple LTCs. ${ }^{16}$ As no PROM exists to capture outcomes across all LTCs, the EuroQol five-dimension questionnaire (EQ-5D) is used in England to assess LTC outcomes, eg, as part of the GP Patient Survey. ${ }^{17}$ However, the EQ-5D may not capture all issues of importance to patients and clinicians. Therefore, professional and lay stakeholders support the development of a new measure for LTCs. ${ }^{18}$ The intention of this measure would be to capture issues of importance across LTCs and to offer a practical, easily interpretable, and useful method to assess outcomes across a range of health and social care services.

The aim was to develop a short self-completed questionnaire about issues of importance when living with LTCs. The intention was to develop a measure for use by adults with single and multiple morbidities, including both physical and mental health conditions. We intend it to be used for individual care and for population monitoring across all health and social care settings. The domains and items are intended to be complementary to those of the EQ-5D, and to reflect both traditional domains (ie, aspects of quality of life) and less traditional domains of importance in LTCs (eg, empowerment) that can be assessed by patient self-report. Following scoping reviews of the literature covering 12 key domains that can be assessed through patient reports and a stakeholder consultation, ${ }^{18}$ an initial conceptual framework was developed (see Table 1 for the initial framework). ${ }^{3,4}$ This article describes the refinement of the conceptual framework and the development of the thematic domains and initial items.

\section{Materials and methods Qualitative interviews}

\section{Recruitment}

Eight primary care practices in England (four in Oxfordshire and four in London) agreed to recruit people with at least one of ten specified LTCs from their patient database. The ten LTCs were selected by a panel composed of the authors, PROM experts, and lay advisors. The aim was to select maximally diverse LTCs (in terms of symptoms, bodily systems, disease trajectory, prevalence, likelihood of comorbidities, burden of disease and care, and level of self-management). To aid this process, the panel was provided with information on bodily systems, the World Health Organization Global Burden of Disease study, ${ }^{19}$ a study on multimorbidity, ${ }^{7}$ and the LTCs included in the Quality and Outcomes Framework (http://www.nice. org.uk/aboutnice/qof/qof.jsp). The following LTCs were selected: cancer, chronic obstructive pulmonary disease (COPD), ischemic heart disease (IHD), diabetes, depression, inflammatory bowel disease (IBD), multiple sclerosis (MS), osteoarthritis, schizophrenia, and stroke. Seven of these were selected by over half the panel, and three (IBD, MS, and schizophrenia) were selected by at least one panel member and included to contrast maximally with the other seven LTCs.

Practice staff conducted a search on the database comprised of the electronic patient record of all individuals registered with the practice. Search criteria were followed according to instructions developed and tested by one of the authors (CA). This search produced a list of patients with the relevant LTCs. Practices fed back the number of patients identified per LTC. The researchers used an online randomization tool (www.random.org) to generate random patient numbers per LTC. Practice staff then selected patients according to the randomization numbers from the list, and checked each patient against the inclusion and exclusion criteria. A total of 360 eligible patients were invited into the study. For LTCs with lifelong implications (COPD, diabetes, IBD, IHD, MS, osteoarthritis, and stroke), eligibility was defined as the presence of the LTC. Where full prolonged 
remission or cure is possible (cancer, depression, and schizophrenia), additional criteria in relation to duration of disease and/or current treatment were determined, similarly to the approach taken by Barnett et al. ${ }^{7}$ Additionally, the diagnosis needed to have been confirmed more than 12 months ago, to ensure that patients had time to adjust to their diagnosis and had experienced a range of services and strategies for the management of their LTC(s). Only adult patients were included (ie, 18 years of age and above). There was no upper age limit.

No participants with schizophrenia were recruited through primary care; therefore, the data were supplemented with interviews from a study conducted in 2013-2014 by RF and MP on outcomes valued by people with schizophrenia. ${ }^{20}$ Participants had been recruited through an email invitation by Rethink Mental Illness (https://www.rethink. org/about-us) and snowball sampling. The exact number of people receiving the invitation is not known, but 47 people made contact to participate. Of these 47, 13 were excluded due to not reporting a diagnosis of schizophrenia or schizoaffective disorder, five people refused to be interviewed, and seven failed to respond to emails after their initial contact. For the purposes of the study presented here, six transcripts of diverse participants (in terms of age and sex) were selected for secondary analysis.

\section{Data collection}

Eligible patients were sent a letter of invitation by the primary care practice and were asked to contact the researchers if they were interested in participating. Following initial contact that included confirmation of eligibility, the researchers arranged an interview time and location according to the preference of the participant; most interviews took place in participants' homes, their workplace, or the University of Oxford. All participants gave written consent. The semi-structured interviews were conducted by $\mathrm{CH}, \mathrm{LK}$, and $\mathrm{CP}$. All interviews were digitally audio-recorded.

The topic guide for the primary care participants (Table 2) was informed by our previous scoping literature reviews on PROMs and the key domains (Table 1), health care-policy documents (such as the National Health Service Outcomes Framework and the Social Care Outcomes Framework), ${ }^{21,22}$ and the stakeholder interviews. ${ }^{18}$ It focused on impacts and outcomes of LTCs, personal self-care strategies, help needed or received in managing LTCs (including experiences of health, social care, or community/voluntary services), and goals or problems regarding LTC management. In later interviews, participants were also invited to comment on emerging themes that were being considered as candidate items for a new PROM for LTCs. The schizophrenia topic guide (Table 2) was developed on the basis of a stakeholder consensus meeting and the literature.

Table 2 Topic guide for interviews

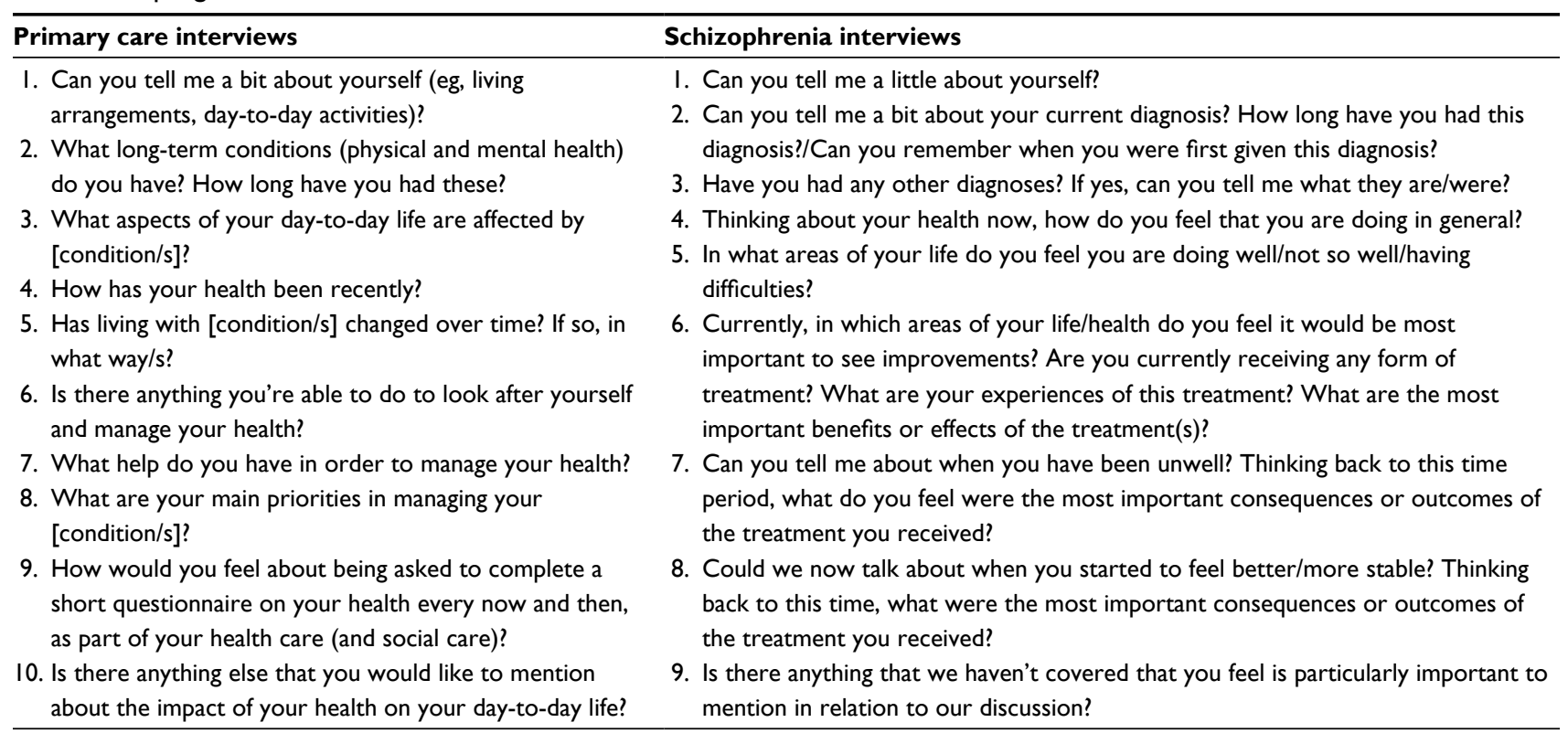




\section{Data analysis and development of items}

The interviews were transcribed verbatim by a professional transcription company. All transcripts were verified and anonymized by the interviewers before analyzing the data in QSR NVivo 10, a qualitative software package. An iterative framework analysis was used..$^{23}$ According to this approach, eight interviews were analyzed according to an initial coding framework drawing on the literature review and the stakeholder interviews. ${ }^{18}$ After discussion among the authors, the coding framework was expanded to take account of emerging themes, particularly those relating to social care; a further 18 interviews were analyzed using the expanded framework. $\mathrm{CH}, \mathrm{CP}$, and LK conducted the analysis, and MP and RF analyzed ten interview transcripts (five each). These ten transcripts were selected to represent a range of LTCs. The analysis framework was then discussed and further refined, before the remaining 22 interview transcripts (including the six schizophrenia transcripts) were analyzed. Once all transcripts had been coded, the framework was reviewed again, with no further changes made. Earlier transcripts were then recoded to incorporate the additional codes from the final framework.

A data-saturation table was created to evaluate if thematic saturation had been achieved. Saturation was defined as "the point in the data collection process when no new conceptrelevant information is being elicited from individual interviews or focus groups". ${ }^{4}$ The interview data were analyzed systematically and subsequently, and concurrently with data collection, using a constant comparison method moving between the codebook, the saturation table, and full transcripts, ${ }^{24}$ to determine if new themes emerged. Data collection was considered complete when no new relevant themes were emerging. As described earlier, the analysis framework was established following a review of the framework based on the analysis of 18 interviews. No further themes were added to the framework during the subsequent analysis.

Individual team members (MP, $\mathrm{CH}, \mathrm{LK}, \mathrm{RF}, \mathrm{CJ}$, and AMT) drafted candidate items based on a number of dimensions. Each dimension represented either one theme or subtheme from the qualitative analysis or two merged themes/subthemes. All the dimensions represented the refined conceptual framework underpinning the new measure. The candidate items were discussed in team meetings to identify and reach consensus on individual candidate items. Criteria for retaining candidate items included that they represented issues identified as important in the interviews (either to all the participants or important subgroups, such as social care users) and that they were deemed clear and easy to understand. Usually, duplicate items or those that significantly overlap (ie, represent similar underlying concepts) would also be removed in this process. However, the first draft of the questionnaire included a small number of items that were duplicates (as they were either worded positively and negatively) or that represented similar concepts. While this meant some items were very similar, it allowed pretesting differently worded items with people with LTCs in cognitive interviews.

\section{Ethical approval}

For the primary care participants, ethical approval was obtained through the National Research Ethics Service Committee London - Bromley. Ethical approval for the schizophrenia study had been gained through the East of Scotland Research Ethics Service. All participants signed an informed consent form.

\section{Results \\ Participants}

A total of 48 people with LTCs (42 recruited through primary care and six through the schizophrenia study) were interviewed (Tables 3 and S1 for details on participants). Participants reported a wide range of LTCs, in addition to the index LTC. Information on the use of social care was only available for the participants recruited through primary care, as the schizophrenia study did not directly ask about this.

\section{The overarching concepts and themes}

Following the analysis, three overarching organizing concepts were identified to focus thinking about the emerging patterns of data in relation to living with LTCs: impact of LTC(s), experiences of services and support, and self-care. The three overarching concepts contained 22 themes; 16 themes were analyzed at this level only, and six themes contained 17 subthemes (Table 4). Impact of LTC(s) encompassed the largest range of themes with 15 themes, experience of services and support included four themes, and self-care was composed of three themes. The majority of the participants discussed aspects of each of the three overarching concepts.

\section{Impact of LTC(s)}

Participants described how their lives had been affected by their LTCs (Table 4). This included such issues as impact on day-to-day activities, emotional or mental well-being, and social participation, mentioned by more than $75 \%$ of 
Table 3 Characteristics of interview participants

\begin{tabular}{|c|c|c|}
\hline & Primary care recruitment & Schizophrenia study \\
\hline Number of interviews & 42 & 6 \\
\hline Sex & 22 men, 20 women & Four men, two women \\
\hline Age range (years) & $30-97$ & $29-60$ \\
\hline Ethnicity & $\begin{array}{l}36 \text { white British or Irish. Also one white European, one Egyptian, } \\
\text { four South Asian }\end{array}$ & $\begin{array}{l}\text { Four white British, one white } \\
\text { European, one black British }\end{array}$ \\
\hline \multicolumn{3}{|l|}{ LTCs } \\
\hline Single morbidity (n) & 18 & 3 \\
\hline Multimorbidity $(n)$ & 24 (range 2-8 LTCs) & 3 (range $2-4$ LTCs) \\
\hline $\begin{array}{l}\text { Participants per LTC determining } \\
\text { recruitment }(n)\end{array}$ & $\begin{array}{l}\text { COPD (three), diabetes (I4), IHD (six), cancer (five), depression (three), } \\
\text { schizophrenia (zero), stroke/TIA (five), IBD (four), MS (seven), OA (ten) }\end{array}$ & A type of schizophrenia (six) \\
\hline All other LTCs reported & $\begin{array}{l}\text { Agoraphobia, asthma, bipolar disorder, borderline personality disorder, } \\
\text { chronic kidney disease, chronic back pain/sciatica, chronic renal failure, } \\
\text { chronic skin condition, diverticulitis, gout, hearing loss, heart failure, } \\
\text { epilepsy, dyslexia, hypertension, hypothyroidism or other thyroid condition, } \\
\text { neurofibromatosis type I, peripheral vascular disease, psoriatic arthritis, } \\
\text { psychosis (drug-induced), spinal stenosis, and visual loss }\end{array}$ & $\begin{array}{l}\text { Anxiety, spinal stenosis, } \\
\text { depression, breast cancer, } \\
\text { and long-term hepatitis C }\end{array}$ \\
\hline Social care use & Seven with some form of social care experience & $\begin{array}{l}\text { Participants were not asked } \\
\text { about use of social care }\end{array}$ \\
\hline
\end{tabular}

Abbreviations: LTCs, long-term conditions; COPD, chronic obstructive pulmonary disease; IHD, ischemic heart disease; TIA, transient ischemic attack; IBD, inflammatory bowel disease; MS, multiple sclerosis; OA, osteoarthritis.

Table 4 The three main overarching concepts, with their themes $(\bullet)$ and subthemes $(0)$ identified within the interviews

\begin{tabular}{|c|c|c|}
\hline Impact of the LTC(s) & Experience of services and support & Self-care \\
\hline $\begin{array}{l}\text { - Achieving personal goals } \\
\text { - Health status } \\
\text { - Impact on day-to-day activities } \\
\text { - Impact on emotional or mental well-being } \\
\text { - Impact on family or carer } \\
\text { - (In)dependence } \\
\text { O Independence } \\
\text { - Dependence/sense of being a burden } \\
\text { - Loneliness } \\
\text { - Physical activity } \\
\text { - Roles and responsibilities } \\
\text { - Safe environment } \\
\text { - Social participation and involvement } \\
\text { - Stigma } \\
\text { o Self-perception } \\
\text { - Social stigma } \\
\text { - Temporal awareness of LTC(s) } \\
\text { - Worry about staying well in the future }\end{array}$ & $\begin{array}{l}\text { - Burden of care } \\
\circ \text { Burden of services } \\
\circ \text { Burden of treatment } \\
\text { - Experiences of services } \\
\circ \text { Sense of being (un)supported by } \\
\text { services } \\
\circ \text { Dignity } \\
\circ \text { Level of expertise of services } \\
\circ \text { Pressure on services } \\
\circ \text { Use of private health care } \\
\text { - Involvement in health decisions } \\
\text { - Social support }\end{array}$ & $\begin{array}{l}\text { - Coping with LTC(s) } \\
\circ \text { Through planning or adjusting to LTC(s) } \\
\circ \text { Reprioritization in light of LTC(s) } \\
\text { - Empowerment } \\
\text { - Self-management in relation to LTC(s) } \\
\circ \text { Confidence to self-manage } \\
\circ \text { Desire to self-manage } \\
\circ \text { Knowledge and/or information to manage } \\
\text { LTC(s) } \\
\circ \text { Skills to manage LTC(s) }\end{array}$ \\
\hline
\end{tabular}

Abbreviation: LTCs, long-term conditions.

participants, to such themes as impact on family or carers and loneliness, discussed by fewer than $35 \%$ of participants (Table 5).

A 64-year-old woman with COPD, stroke, arthritis, agoraphobia, depression, IHD, gout, and stenosis of the spine described the impact of her LTC(s) on her physical health and daily activities:

[...] I can dress myself, except for when it comes to my feet, because I can't get that far on my back, and my knees don't move properly [...] so I can't do that [...]. I'll cook with a microwave, but I can't prepare vegetables, but I can cook, but I can't hold hot saucepans, and hot things, so if it's just a matter of putting something in a microwave, I can do that. I just look to do the things I can do, like I can dust, my husband hoovers, I can't manage the Hoover [...].

The ability to achieve personal goals was discussed by over half of the participants. Personal goals could relate to anything that participants valued; however, mostly it centered on work and family, but could also focus on the ability to look after pets or keep up with hobbies or physical activity. 
Table 5 Themes, subthemes, numbers, and rank of interviews endorsing theme

\begin{tabular}{|c|c|c|c|c|c|}
\hline Theme & Subtheme & $\begin{array}{l}\text { Schizophrenia } \\
(n=6)\end{array}$ & $\begin{array}{l}\text { LTC } \\
(n=42)\end{array}$ & $\begin{array}{l}\text { Total } \\
(n=48)\end{array}$ & Rank \\
\hline Experiences of services & Sense of being (un)supported by services & 6 & 41 & 47 & $\mathbf{I}$ \\
\hline Impact on day-to-day activities & & 5 & 41 & 46 & 2 \\
\hline Social support & & 6 & 38 & 44 & 3 \\
\hline $\begin{array}{l}\text { Social participation and } \\
\text { involvement }\end{array}$ & & 6 & 37 & 43 & 4 \\
\hline $\begin{array}{l}\text { Impact on emotional or } \\
\text { mental well-being }\end{array}$ & & 6 & 36 & 42 & 5 \\
\hline Coping with LTC(s) & & 5 & 35 & 40 & 6 \\
\hline Self-management & $\begin{array}{l}\text { Knowledge and/or information to manage } \\
\text { LTC(s) }\end{array}$ & 4 & 36 & 40 & 6 \\
\hline Burden of care & Treatment burden & 6 & 32 & 38 & 8 \\
\hline Achieving personal goals & & 6 & 30 & 36 & 9 \\
\hline Self-management & Skills to manage LTC(s) & 3 & 32 & 35 & 10 \\
\hline $\begin{array}{l}\text { Empowerment: a sense of } \\
\text { control over one's daily life }\end{array}$ & & 5 & 28 & 33 & II \\
\hline Self-management & Desire to self-manage & 2 & 30 & 32 & 12 \\
\hline Physical activity & & 2 & 28 & 30 & 13 \\
\hline Self-management & Confidence to manage LTC(s) & 3 & 26 & 29 & 14 \\
\hline Burden of care & Service burden & 3 & 25 & 28 & 15 \\
\hline Stigma & Social stigma & 5 & 22 & 27 & 16 \\
\hline Roles and responsibility & & 2 & 25 & 27 & 16 \\
\hline (In)dependence & Independence & 2 & 25 & 27 & 16 \\
\hline Stigma & Self-perception & 4 & 19 & 23 & 19 \\
\hline Health-status ratings & & 2 & 21 & 23 & 19 \\
\hline Experience of services & Level of expertise from services & 3 & 19 & 22 & 21 \\
\hline Coping with LTC(s) & Coping through planning or adjusting way of living & 3 & 18 & 21 & 22 \\
\hline Worry about staying well in future & & 2 & 17 & 19 & 23 \\
\hline Experience of services & Dignity (how you are treated by services) & $\mathbf{I}$ & 17 & 18 & 24 \\
\hline Safe environment & & 3 & 15 & 18 & 24 \\
\hline (In)dependence & Dependence or being a burden & $\mathbf{I}$ & 16 & 17 & 26 \\
\hline Involvement in health decisions & & 4 & 13 & 17 & 26 \\
\hline Impact on family or carer & & 2 & 13 & 15 & 28 \\
\hline Suitability of home & & 0 & 15 & 15 & 28 \\
\hline $\begin{array}{l}\text { Self-management (especially } \\
\text { relating to } L T C[s] \text { ) }\end{array}$ & & 1 & 13 & 14 & 30 \\
\hline Temporal awareness of LTC(s) & & 1 & 13 & 14 & 30 \\
\hline Loneliness & & 0 & 12 & 12 & 32 \\
\hline Experience of services & Services as pressured - sense of responsibility & 2 & 9 & 11 & 33 \\
\hline Experience of services & Using private health care - reasons & 0 & 11 & 11 & 33 \\
\hline Coping with LTC(s) & Reprioritization in light of LTC(s) & 2 & 8 & 10 & 35 \\
\hline
\end{tabular}

Note: Themes/subthemes in bold were considered for item development.

Abbreviation: LTCs, long-term conditions.

A 58-year-old woman explained how schizophrenia impacted on her work:

[...] I have a degree in psychology, I am a qualified counselor; I wanted to become an analyst. I mean, my career: every time I had a breakdown, it falls apart [...].

Maintenance of independence or becoming dependent formed a significant part of the impact of LTC(s). A 65-year-old woman with MS explained how a parking permit for disabled drivers helped her keep mobile and independent:

[...] I have a condition which is incurable, and in general what happens is you just get worse until you end up in a wheelchair, so I mean obviously my priority is keeping mobile, keeping independent, so independence and mobility is what would be my aim [...]. I think I'm independent, but frankly my blue badge is important to me for independence [...]. 


\section{Experiences of services and support}

In this concept, participants described the types of health and/or social care services they had used, their various types of support, and the burden caused by the services and care needed to manage their LTC(s). Support included help given by people or organizations outside health and social services, such as family members, friends or charities. The most frequently discussed themes (by over $75 \%$ of participants) were support by either services or others, and burden of treatment (Table 5). A 77-year-old man with IHD explained how hospital appointments could be difficult to manage:

[...] and it's also planning sort of like work around hospital [...]. I seem to have so many hospital appointments these days, just seem to be [...] I get the impression that once they get hold of you, they're never going to let you go [...].

In contrast, a 69-year-old man with cancer had found the input by health services helpful:

[...] impressed with the health service. One of the things that's difficult I personally think is, like most others I suspect, it's difficult to get a GP appointment when you actually want one, but I think once you've been identified as having something they have to treat, or believe that they will be able to help with treatment, I have to say I haven't looked back. The treatment and care and the response I get from even the GP, I was transformed by that [...].

Additionally, as to whether services provide adequate support, participants also talked about how they were treated by health care professionals. A 66-year-old woman with cancer and IBD talked about contrasting experiences when consulting different doctors:

[...] there was only the two main doctors: the first one [doctor], he seemed very abrupt, very "doctorerfied" if that makes sense, whereas the other one was very casual in his mannerisms, and you felt you could talk to him [...].

However, it is not only health services that provide support. The importance of social support is explained by a 35 -yearold male with IBD and chronic renal failure:

[...] we travel a lot. That's partly because actually my wife forces me to, or has forced me to, and now I do it a lot more, and I enjoy it and I get a lot out of it. One role of the partner I think is potentially quite interesting: you know, I've had some amazing travel experiences over the last 4 years, partly because I'm with somebody I don't worry as much about what might happen if I were ill and I was away, and also she absorbs [...] quite a lot of my angst, so that enables me to do those things [...].

\section{Self-care}

Self-care focused on actions or strategies that participants used to look after themselves and their LTC(s) or strategies to cope with their LTC(s). This included both active strategies, such as planning around the LTC(s), or passive strategies, such as acceptance of their limitations and reframing priorities. The most widely discussed theme (by over $75 \%$ of participants) was coping with LTC(s). Self-care had the potential to influence positively or negatively the impact of LTC(s). Participants differed in the extent to which they felt able to take positive actions, such as adopting healthier behaviors. There was also a time impact, with participants discussing variations in how well they could self-care during different time periods. When participants struggled with self-care, other problems could occur or the impact of LTC(s) could increase, or worsen the impact of the LTC(s), as explained by a 31-yearold man with depression and medication-induced psychosis:

[...] I've still got depression, I fight every day, I do fight it every day, but before where I'd let it sort of overtake me [...]. I could sit indoors for 2 weeks. I think there was about a time of 2-3 months where I was going to bed at 12 o'clock in the day and sleeping until 9 o'clock at night and then I'd wake up, and I'd sit the whole night like just watching TV, and all I'd eat was a bowl of Weetabix. I went down to 9 stone, I looked anorexic, and it just spiraled out of control [...].

A certain degree of own judgment and flexibility was often needed to find the best way to deal with the LTC(s). A 68-year-old woman described how she adapted to cope with the dietary changes needed to manage her diabetes:

[...] Initially I had to reeducate myself diet-wise [...] by nature I have a very bad sweet tooth, so I had to restrict my intake of sweets. But otherwise it wasn't [...] but I'm somebody [that] once I know I have to do something, I condition my mind and just get on with it [...].

Acceptance of LTC(s), and the limitations this might impose, was explained by a 72-year-old man with four different morbidities, including diabetes and arthritis:

[...] I've had these various problems, starting with polio and asthma when I was very young. I've missed a fair bit of schooling through the polio, you just get sort of used to it, 
and you get one more thing to put up with and you get on with it. There's no point in sitting around: you've got to make the best of things and you know, and fight back basically [...].

\section{Item development}

As it is the intention to develop a short measure for LTCs, it was not feasible to include items for each theme or subtheme from the interviews, although the three organizing concepts are represented in the items. Twenty themes or subthemes were taken into account in item development. These 20 themes or subthemes mostly ranked highly in terms of the number of interviews in which they were discussed. The lowest level of analysis was used for the ranking, meaning 18 themes and 17 subthemes. The 20 themes/subthemes selected for item development are highlighted in bold in Table 5, and they underpinned 17 dimensions (some themes collapsed for item development, eg, "Impact on day-to-day activities" and "Impact on emotional or mental well-being" were collapsed into "Impact of LTCs") that were used to develop items (Table 6). The dimensions, representing the refined conceptual

Table 6 LTCQ dimensions, qualitative themes, and illustrative quotes

\begin{tabular}{ll}
\hline Impact of LTCs & \\
\hline LTCQ & $\begin{array}{l}\text { Definition (coding } \\
\text { framework) }\end{array}$ \\
\hline Achieving & Any personal goals (ie, \\
personal goals & something participants \\
& talk about valuing or \\
& wishing they could do) \\
& and how LTC(s) impact \\
& on ability to achieve \\
& personal goals or how \\
goals have changed due & to the LTC(s) \\
Feelings of being too \\
Dependence and \\
being a burden & $\begin{array}{l}\text { dependent on others } \\
\text { for basic or other } \\
\text { needs, eg, feeling like } \\
\text { a burden, unhappiness } \\
\text { about having to rely on } \\
\text { others, future fears of } \\
\text { dependence }\end{array}$ \\
\end{tabular}

Examples from the qualitative interviews

"[...]. The arthritis, yes, it does, at the moment, with the damp weather and things. I'm waiting for a knee replacement, and my knee is giving me so much [...] restricting my movement quite a bit. l'm in quite a bit of agony and it restricts my movement, which is annoying me, because l'm not someone who can sit for long periods doing nothing, but this is forcing me to do that, which I really am not enjoying at all [...].” [68-year-old woman with diabetes and psoriatic arthritis]

"[...]. I want to be able to carry on walking the dogs properly and we have - believe it not - there's a swimming pool out there. l'd like to be able to keep swimming, because that's such good exercise [...]." [54-year-old woman with MS]

“[...]. Pretty much I look after myself. I do all my own cooking and stuff, so I manage the diabetes, nobody else gets involved with that. I do all the injections and put all my tablets out, and so I do all that myself [...].” [59-year-old man with diabetes]

“[...]. It's just been the same. I don't think anything's really changed, except for the fact that as time goes by I seem to get less and less independent [...]. I've been used to being independent, and losing that independence has been the hardest thing in the world [...]." [64-year-old woman with MS, arthritis, stroke, and problems with vision] “[...]. As long as I live, I want to be fairly healthy for them [family], so I'm not a burden [...]." [76-yearold woman with COPD, asthma, OA, diverticulitis, and depression]

"[...] we have done holidays with friends, and you just feel very conscious that if I'm there, I'm restricting what they can all do. It's not just me, it affects everybody else [...] you know we're aware that all the others are thinking that they'd like to go off and see this thing, or do that thing, and you tend to really hold back and try and persuade - 'Just go, don't worry about us going, you do it' you know, and I feel hard done by, but I don't want to put the extra burden on other people [...]." [55-year-old woman with MS]

Impact of LTC(s) Impact LTC(s) have on ability to complete day-to-day activities (like cooking, cleaning, work, self-care, looking after family/pets) and impact on emotional health and mental state, including LTCs causing anxiety/worry, feeling depressed as a result of LTCs, difficulties concentrating, etc. “[...]. [It] made me think, 'If I don't take my medicines this time, I'm going to have a newborn and a 5-year-old at home, and l'm going to be in hospital, and there's no one to take care of them." Do you know what I mean? So since then, since that one attack during pregnancy, l've been taking my remission medication like it's a religion [...]." [33-year-old woman with IBD (ulcerative colitis)] "[...]. I do arrow words and crosswords just to keep my brain going, because l've got this stupid memory that drives me absolutely silly, and I keep thinking, 'Well, I don't know, as long as do things like that, it'll keep my brain moving', and I do tend to do a lot of those. It makes me relax, to be quite honest, because I used to be really, really fit, really, really busy, you know, I never had time to sit around or anything, but now l'm stuck because l've got all this time and I don't really want it, so l've got to fill it in or else I get depressed [...]." [64-year-old woman with COPD, stroke, arthritis, agoraphobia, depression, IHD, gout, and stenosis of the spine]

" [...] perhaps when I was at university, various things where I was convinced that I really wasn't, you know, I was the lowest of the low, and I had absolutely no self-esteem whatsoever and I couldn't believe it if, you know, a bloke chatted me up, I thought he was only after my good-looking friend, or whatever, and times when l've, you know, just been convinced that people have only sort of put up with having me around for one reason or another, rather than actually being genuine friends, and I look back on that and think, 'Well, yeah, that's [...] you were depressed at that point' [...]." [44-year-old woman with depression and OA] 


\section{Impact of LTCs}

\section{LTCQ Definition (coding Examples from the qualitative interviews}

dimensions framework)

Loneliness

Physical activity

Impact of LTC(s) on physical activity levels; this might overlap with impact on day-to day-activities, as these often require physical activity, but additionally includes exercise as a physical activity undertaken for health or leisure purposes

Roles and responsibilities

Safe environment

\section{Impact of LTC(s)}

on a person's ability to undertake valued social roles and where LTC(s) affects their ability to take on or fulfill responsibilities, eg, parenting, family duties, work, or community responsibilities

\section{The extent to which} people feel safe or unsafe in relation to inside and outside their home, in particular when this is health-related, eg, falls in the home; from a social services perspective, people may also feel unsafe for other reasons, eg, fear of abuse, crime, etc knee replacement, and sciatica] vision] depression, and spinal stenosis] chronic skin condition] the spine]
"[...]. I'm very lucky, I say, in having [neighbor] next door to me. That's because there is nobody else up here that could be the same as him next door, you know, where I can go in, have a little chat, discuss what's in the paper, and that sort of thing, and that, believe me, is a big thing when you're stuck up here all day long [...]." [97-year-old woman with OA, hypertension, hearing loss, chronic back pain,

"[...]. It's quite funny, really. And if it wasn't for my son visiting twice a day, and my dog and my cat, there'd be nothing in my life, really, you'd just be sitting here looking out the window or watching the television, and that'd be it [...]." [64-year-old woman with MS, arthritis, stroke, and problems with

"[...] I must admit I am quite, um, content with my own company when I'm not doing anything [...]. But I do like company from time to time [...]." [45-year-old man with paranoid schizophrenia, anxiety,

"[...] I have a friend who lives very high up and there are no lifts. There's 84 steps, and it's just too much for me, I am out of breath at the top of that. Steep hills are a bit of a problem [...]." [76-year-old woman with COPD, asthma, OA, diverticulitis, and depression]

"[...] I used to walk miles. I ended up walking with the aid of a stick, but before that I could walk miles. I think it sort of descended on me suddenly, and I don't know why, and I couldn't walk without the aid of a stick or a frame, and that reduced my activity right down [...]." [87-year-old man with cancer and

"[...] 'cos you feel like you want to do some exercise, just to keep some sort of fitness, but because of the fatigue side of things, it just took over too much of life, because I would do the gym, then come home, be completely wiped out, couldn't do anything [...] so [gym] three times [a week]. I think the MS physio, I think she said she thought that was too much, so l've cut it down now to once a week, and that's only about half an hour, which half of me thinks, 'Is there any point me doing that?', 'cos it's such a tiny thing, I sort of half feel it's not worth doing [...]." [55-year-old woman with MS]

“[...] I didn't want to leave work, but since 2007 l've just not been well, one thing after another, and I just had to give up my job, which wasn't great for me, because I loved my job [...]. Loved it, really loved it, but then I started to get sick, this, that, and the other, and in the end it wasn't fair on them and it wasn't fair on me. So my husband's struggling a bit, so I thought, 'No, this has got to stop', so I was of retirement age anyway, well nearly, so, you know, I just had to bite the bullet, as you do [...]." [64-year-old woman with COPD, stroke, arthritis, agoraphobia, depression, IHD, gout, and stenosis of

"[...] I have to take the wife to do the shopping. I can't go in with her because it's too far to walk, you know, so I have to sit in the car, and I can't take the dogs round the park anymore, that upsets me quite a bit [...]." [70-year-old man with diabetes, OA, stroke, angina, hypertension, and cancer]

“[...] I've slowly but surely got worse over the years, my walking is a joke. I can't [...] I do go out, but I'm very nervous the whole time, because this foot goes out to the side and l've got no muscles to keep it over [...]. I've not got the freedom I used to have, because I'm scared to go out on my own now. I have to go out, thank goodness, because l've got [dog] to walk in the mornings, and my son comes in, takes him out at night for a long run, but l've found I need to keep my head up and look where I want to go, because if I look down or look around, I can get dizzy and lose where I am [...]." [64 year old woman with MS, arthritis, stroke, and problems with vision] "[...] I had had a fall down these three steps, and I couldn't get to my phone. I had to loaf around on the floor all night. I got to the fridge, I got a pint of milk out of there, and I waited for the paperboy to come in the morning [...]." [88-year-old man with diabetes, COPD, OA, and hypertension] "[...]. [It] depends where you live, doesn't it? I feel quite safe round here. I know it's a bad area, but it's what l'm used to. I would feel less safe in somewhere like somewhere posh, because of people's attitudes [...]." [49-year-old woman with diabetes, borderline personality disorder, and sciatica] 
Table 6 (Continued)

\begin{tabular}{ll}
\hline Impact of LTCs & \\
\hline dimen & $\begin{array}{l}\text { Definition (coding } \\
\text { framework) }\end{array}$ \\
\hline Social & Social activities and any \\
participation & social involvement that \\
& people value that are \\
& negatively or positively \\
& affected by LTC(s), eg, \\
& family-related activities, \\
& activities with friends, \\
& and voluntary activities \\
& or work-related \\
& activities that are \\
& valued for the social \\
& aspect
\end{tabular}

Stigma Negative judgments or worries about negative judgments upon a person by virtue of LTCs including internal (people view themselves less positively or negatively) and external stigma (perceived negatively by other people)

Suitability of Any problems with home

\section{Examples from the qualitative interviews}

"[...] I guess I could be a bit more sociable sometimes, but half the times I don't know if I can really [...] if I'm really in the mood to do anything [...]." [29-year-old woman with paranoid schizophrenia and depression]

"[...] I also meet up with a group of people that have MS. They meet up once a month in the evening, go have dinner [...] [husband] said he'd rather stick his head in the sand, pretend it wasn't happening, whereas I just wanted to just meet other people, and my sister said, 'Trust you to make it a social occasion' [laughs] [...].” [45-year-old woman with MS]

"[...]. The people I know and socialize with know that I have a limitation, and they take that into consideration. Sometimes it's forgotten, but l'll do things at my own pace. We go out once a month, a group of lads from the village here, go out on a beer and curry night, into [...] We take in our local pub, then we have a coach take us into [city] [...] there is a bit of walking once the coach has dropped us off. There was one particular evening, where the walk was a bit further and I was struggling. So we got a taxi, it was called a police car [laughs], took me to the curry house. It took a bit of explaining to get it done, but they did get it done, because I can take that lightheartedly, but I would have got there anyway, but it would have taken just another 10-15 minutes for me to get there. I wouldn't have tried to keep up with people, that's the key. If we're out walking, I will do it at my pace, and if I need to rest, I'll rest. Therefore, I won't let it get too uncomfortable. I can feel it coming on, and just slow down, take a rest, as I need to [...]." [59-year-old man with diabetes, arthritis, and circulatory problems] "[...]. Everybody started talking about me, saying rumors, and saying I was thick, and, you know, sort of saying I was bent and all that sort of thing; and then I got a complex about myself [...]." [45-year-old man with paranoid schizophrenia, anxiety, depression, and spinal stenosis]

"[...] there's things sort of like when you have questionnaires to do with mortgage and whatever, life insurance, and when you're talking to a financial advisor, they go, 'Oh, yeah, we've just got the quick questionnaire to do, and, you know, obviously you've never suffered from this, this, this, and this', and you say, 'Well, actually yeah, l'm on antidepressants and probably will be for the rest of my life', and you can see this sort of 'Oh, you poor thing' and 'Oh crumbs, what do I say now?' kind of look on people's faces. But again, l've got less sensitive about that, and as years go by, you always think, 'Well, yeah it's just part of me that doesn't quite work properly' [...]." [44-year-old woman with depression and osteoarthritis]

“[...] I don't feel that stigma. I think, 'Well, that's your problem if you think you know that l'm different' [...]. Just to give you an anecdote, when I was first diagnosed with MS, I went to [...] announce it to my parents, and when I said, 'l've been diagnosed with MS' and explained what it meant, my father's reaction was, 'Don't you find that very embarrassing?' And I thought, 'No, I don't', and I've never found it embarrassing; I don't feel embarrassed. You know, I'm a man, I have sexual problems: do I find that embarrassing? No, it's just a fact [...]." [67-year-old man with MS]

"[...] We got an extra banister, a wall banister, going up the stair, and I tend to hold onto both when I'm going up and down. I feel going up and down is quite good for me [...]." [65-year-old woman with $\mathrm{MS}]$

“[...] can't go out walking with the dogs because of my legs, and there's several things I can't do, but it's a struggle sometimes to get upstairs. I've had one or two accidents because I couldn't make it upstairs quick enough [laughs]. A bit silly, but you don't really want to know about that do you [...]." [70-yearold man with diabetes, OA, stroke, angina, hypertension, and cancer]

“[...] the house, I mean, I don't think it's too bad: it's clean, a bit cluttered, I suppose, with gadgets for the animals. I want to be comfortable, I'm stuck in a lot, I want to be comfortable, and I can't be any more comfortable, I don't think, and this is my cocoon, this house, 'cos I mean there's some days I just don't want to go out of it [...]." [64-year-old woman with COPD, stroke, arthritis, agoraphobia, depression, IHD, gout, and stenosis of the spine] 


\section{Experiences of services and support}

LTCQ Definition (coding Examples from the qualitative interviews

dimensions framework)

Burden of Burden of treatment is

treatment and

services

Dignity

Support Any support people with $\mathrm{LTC}(\mathrm{s})$ receive or do not receive, including help by health and social services and support by significant others, such as family, friends, neighbors, work colleagues paranoid schizophrenia and depression] renal failure] stroke, and problems with vision]
“[...] l'm seen bimonthly by the renal team at [hospital], so l'm in hospital as an outpatient on average once a month because I go in, twice every 2 months, if you see what I mean. I'll go in once to have some blood tests and then back again a week or so later for a clinic, so that's 12 times a year. So I'm in hospital very regularly, go to my GP as needed, very regular blood tests, administration and medication that I can't give myself, I'm on a range of medication that supports both how I feel but also to keep my kidney function as good as possible, so I have to inject myself weekly with a hormone called EPO, which you probably know about, on top of the tablets, then they give me injections of the iron when needed. That's about it really [...]." [35-year-old man with IBD and chronic renal failure]

"[...] I don't go to the doctors often, to be honest, but I have appointments up the [hospital] for the diabetes, every 6 months, and I go to the heart clinic once a year. That's not too bad, but it can be annoying when you have to go to the doctors, but it's not too bad [...]." [70-year-old man with diabetes, stroke, IHD, gout, and chronic back pain]

"[...] It's just the side effects of it, and it's a bit, it's annoying because I have actually [...] you know, I have asked whether my medication can be changed to something completely different but they're [...] their feeling is that they don't, they think the [um], they don't think that's a very good idea. They don't think the side effects of that are severe enough for me to change [...]." [29-year-old woman with

"[...] the worst thing for me was after I had my operation - this was another bug bear of mine - I was told beforehand that there were cancerous nodes, and that's why they had to be removed [...] from the day I was diagnosed, the doctor sent to me to the specialist. I was like a hamster on a wheel: I couldn't get off, you know it's going to happen, but you can't stop it [laughs], and after the operation was done, this woman came in and she pulled the curtains round me, and she said, "By the way, you're diagnosed with cancer", and she walked out and she left me with that, and for me it was just a brick that she had hit me with, and I was so angry, I really was. I saw red and afterwards I just cried and cried and cried, and when somebody asked me "Why?" and I tried to tell them, they went "What?" I said "yes". I sincerely hope and trust that they take them to task about it, because that's an awful thing to do to anybody [...]." [70-year-old woman with diabetes and thyroid problems]

"[...] there was a time a little while ago when I was starting to feel really quite down by it, and I just had a great chat with my GP about it, and about what to do and you know, and possible therapy options and what we could do if things got worse, which they didn't. Yeah, they're very, very pleasant people working in an imperfect system, but they are excellent in that they understand [...]. I think they understand very well the nature of chronic conditions [...]." [35-year-old man with IBD and chronic

"[...] I get tired [...] I'm trying to take it easier, 'cos I like working hard and doing it all myself [laughs], but I have to let others do stuff for me [...]" [45-year-old woman with MS]

"[...] you come away from somewhere like the doctor or a consultant, and you think, 'What was the flaming point of all that?' He doesn't [...] he's [...] they're only interested in what is physically wrong, they don't want to probe what impact it's had on you [...]." [64-year-old woman with MS, arthritis,

"[...]. There's some people who know about the chinks in my armor, and that's fine, and strangely enough I was with one yesterday afternoon, who I hadn't seen for a while, because we used to sit next to each other when we worked [together] [...]. She knew, just by my mood, if there was something [...] if my blood sugars were dropping or if there was something wrong and she would say, 'Have you checked your blood sugar?', and I actually said to her yesterday how I miss that so much, but she just knew by how I was what was going on, but, you know, we don't work together anymore, and it was funny, at the time, I kept saying, 'Oh, [name], don't fuss', but I realize I did really appreciate that a lot [...].” [58-year-old woman with diabetes and asthma] 
Table 6 (Continued)

\begin{tabular}{ll}
\hline Self-care & Definition (coding \\
\hline dimensions & framework) \\
\hline Coping & Any tactics or methods \\
& used to cope with \\
& LTC(s), such as \\
& accepting the LTC(s) \\
& or finding different \\
& ways of doing things; \\
& can include problems \\
& or difficulties that \\
& lead to people not \\
& coping with LTC(s) and \\
& emotional responses \\
& to LTC(s), eg, feeling \\
& overwhelmed or \\
frustrated
\end{tabular}

Empowerment/ Feeling empowered sense of control and in control and the process of being enabled to be in control of life through support and help by treatments, services, and other people

Information and The resources people knowledge have or need to understand and manage their LTC(s)
Confidence to manage LTC(s)
Confidence or a lack of confidence (could be anxiety or feeling overwhelmed or confused) to manage LTC(s) and/or any treatments and/or any medications in relation to their LTC(s)
Examples from the qualitative interviews

"[...] do I regret the things I can't do? No, I just can't do them, so, you know, even if I hadn't had MS, I would never have been able to climb mountains. Do I regret I can't climb mountains? No, I just can't do them, so I apply that to other things, you know, I'm getting older, I've lost all my youth, do I regret losing all of my youth? No, not really. Things just move on, and I cope with what l've got [...]." [33-year-old woman with IBD (ulcerative colitis)]

"[...] I stay on these tablets I'm on. They tried me to go back on some others that are not so potent, but every time I take them I get the diarrhea, so I had to stop taking them [...] you do live in a little bit of a fear of you might go to the toilet any time of the day, and I don't wear pads very often now. I chance it and hope for the best, but I do wear them occasionally if I'm going to go on a long journey, like I went on holiday, and yes I wore when, when I was on the plane, well you think, 'I could get stuck on the plane' [...]. I always carry pads and cleaning stuff with me, all the time, because I never know when I might just suddenly go, and I need to clean myself up and I have been caught out when l've been on walks, along the sea coast and things, l've got caught out and had to find a loo, and change my knickers or chuck my knickers away, and put new ones on: catches you out, you know. I live with it. I don't say it's good, but I live with it at the moment [...]." [66-year-old woman with IBD (ulcerative colitis) and cancer]

"[...] l'm in control of everything, completely, not just my life, a lot of the people around me will come to me for advice and steer them [...]." [59-year-old man with type 2 diabetes]

"[...] I mean the more dialogue there is about long-term illnesses, I would have thought the better. The more real dialogue, well for me it's important, and whether it is for other people, but for me it's the importance of as l've said already, of being engaged in it, and feeling that it's under my control, and that I have a big say in what's done to me [...]." [69-year-old man with IHD]

"[...] access to better information. I think that's something the NHS tends to neglect. The GPs tend to have information that they impart, when they want to impart to you when you're, you know, in your 10-minute consultation you get [very little] information during that time. Sometimes, they give you some articles they get off the web, they print out for you, but generally speaking, that sort of level of information is fine, but I tend to want more information [...]." [7/-year-old man with diabetes and cancer]

"[...] I think a lot of people find it difficult to find out information from social services, about what they're entitled to, rather than what they can get, but what they are entitled to. I wouldn't know if I was entitled to any help or not, not now but in the future, people don't know, a lot of people don't know [...]." [70-year-old man with type 2 diabetes, stroke, IHD, gout, and chronic back pain] "[...] you've got a colitis [society] that you can join. I think it's a booklet they send you, every so often, and you can read about other people, or you can go to meetings and meet people. I'm not saying you do, but you can. There are obviously associations around, where you can go and talk about your problems, or what's going on in your life, and you get these books, and they tell you about it, and the hospital gives you three or four booklets when you come out, that tells you sort of about it, and tries to describe what's it like and what it's not like [...]." [66-year-old woman with IBD (ulcerative colitis) and cancer]

"[...] it's really down to the person at the end of the day. You can be talking to goodness knows how many people about how you're feeling and this, that, and the other, but really and truly if you're not really ready to make a change or you're not well enough to make a change or whatever, nothing $[\ldots]$ it's not going to make no difference [...]" [29-year-old woman with paranoid schizophrenia and depression]

"[...] I increased my walking, and sometimes I think, 'Cut down on the sweets', 'Cut down on the sugar', and things like that, you know. But apart from that, some time I find that I need a bit of sugar, my body will ask, and then I say, 'Well, why did I do that?', and then when you do it, then you find that and you know that your level was going low, or whatever. You become a doctor for yourself [...]." [75-year-old man with IHD]

"[...] I believe I manage my diabetes quite well, hence why I'm not having constant hypos and I'm not having [...]. I try and watch out for it going too high. I don't test myself every 5 minutes, but l've learnt how my body feels, and I can tell when things are not quite right [...]." [59-year-old man with diabetes, arthritis, and circulatory problems]

Abbreviations: LTC, long-term condition; LTCQ, Long-Term Conditions Questionnaire; MS, multiple sclerosis; COPD, chronic obstructive pulmonary disease; OA, osteoarthritis; IHD, ischemic heart disease; EPO, erythropoietin; IBD, inflammatory bowel disease; NHS, National Health Service; GP, general practitioner. 
framework on which item development was based, are defined in Table 6, together with further illustrative quotes from the interviews. Themes that ranked less highly either significantly overlapped (ie, represented a similar underlying concept) with a more highly ranked theme (such as loneliness overlapping with social participation) or they were considered important for less represented groups in the sample. In line with the aim to develop a short measure, a small number of items (one to three) were developed per dimension to give a total of 23 initial items. These 23 items will undergo cognitive testing in further interviews with people with LTCs.

\section{Discussion}

The aim of this study was to develop a measure for LTCs. The aim of this new PROM is to be relevant to adults with single or multiple LTCs (both physical and mental health conditions) and is intended for use at both an individual and a population-based level across all health and social care services. This qualitative study served to refine further the conceptual framework that was initially developed on the basis of literature reviews and stakeholder interviews. The use of in-depth qualitative interviews serves to enhance content validity of a newly developed measure. ${ }^{25}$

The in-depth interviews identified outcomes of importance to people with single and multiple morbidities. Due to the sampling strategies, the ten preselected LTCs were more commonly represented, but 23 additional morbidities were reported by the participants. The ten LTCs were chosen on the basis of their diversity, and together with other reported morbidities, a good spread of LTCs was reported by the 48 participants. The interviews generated rich data on a wide range of issues of importance to outcomes in LTC(s). These themes and subthemes formed three concepts: impact of LTC(s), experiences of services and support, and self-care.

Many of the themes, in particular those coded in "Impact of LTC(s)", resonate with those that are often included in PROMs $;{ }^{26}$ however, some themes, such as self-management, empowerment, experiences of services, suitability of housing, or safety, may be explored less frequently as part of a PROM. These latter outcomes represent outcomes of care, rather than the more traditional outcomes of the condition or disease, but they are nonetheless important in LTCs. Also, these are frequently assessed by patient self-report, eg, self-management can be assessed by the Self-Management Ability Scale (SMAS)-30 questionnaire. ${ }^{27}$ Empowerment, on the other hand, is still considered ill-defined, and the need for a specific PROM to assess empowerment has been identified. ${ }^{28}$ Some would argue that experience of services is a process, not an outcome; however, recently it is becoming more widely recognized that health care and treatment, in particular in multimorbidity, can place a burden on people. ${ }^{29}$ Therefore, as the new measure intends to cover a broad range of issues of relevance in potentially very diverse LTCs, these issues have been included in the item development. The majority of themes/subthemes that underpinned item development ranked highly in terms of the number of participants who discussed them. There were some exceptions, eg, loneliness, safety, and suitability of housing, were talked about by fewer participants. However, these are considered important, either due to their impact on LTCs or due to their relevance to specific groups of people with LTCs. For example, such issues as suitability of housing and safety are of high importance for social care recipients, as demonstrated by the fact that such items are included in the Adult Social Care Outcomes Toolkit (ASCOT). ${ }^{30}$ Therefore, items based on these themes were also developed for the Long-Term Conditions Questionnaire (LTCQ).

While some PROMs, such as the SMAS-30 or the ASCOT, give scope to assess specific outcomes (selfmanagement and outcomes in social care, respectively) in more depth, the ambition of the new measure is to be short and practical while assessing issues of importance in a wide range of LTCs. If outcomes in LTCs are to be assessed within clinical care or on a routine basis, it would not be practical if multiple different tools needed to be used with the same patient and across health and social care services. The items developed for the measure include less traditional but important outcomes. It is hoped that this approach will result in making the LTCQ a measure that is practical for use in the context of clinical care and routine PROM data collection. The candidate items for the new measure will be pretested in cognitive interviews before a large-scale survey is conducted to test the psychometric properties of the measure.

Some limitations of the study need to be acknowledged. First, although the sample included participants with a wide range of LTCs, there were proportionally fewer participants with mental health problems and few participants with experience of social care. This was not unexpected, as they represent smaller groups of people. In the process of selecting themes and refining the conceptual framework, it was ensured that themes that were valued by participants who were less represented were not excluded on the basis that they were not discussed by the majority of the participants. Also, the mental health sample was supplemented by interviews from a study on outcomes in schizophrenia, as no patient with schizophrenia invited through primary care agreed to participate. Although the method of recruitment and interview-topic guides differed 
between the two studies, many issues of importance (eg, treatment burden) overlapped with those reported in the primary care sample, as shown in Table 5. Also, plans for future testing will aim to include larger samples of people with mental health conditions and social care experience. A second limitation might be that a single method of data collection was used. Differences may have been found through using focus groups, although the extensive literature searches and stakeholder consultations give confidence that the main issues of importance for LTCs have been covered. A final limitation may be that LTCs were self-reported, even though participants were selected by GP practices on the basis of a formal diagnosis of a specific LTC. Participants may not have reported all their LTC(s), and issues of importance in relation to these would not have been discussed. Nevertheless, a wide range of LTCs has been included, and thematic saturation was achieved in the interviews. This gives confidence that the main issues of LTCs have been included, and that the resulting measure will have wide relevance.

\section{Conclusion}

This article describes the development of items for a new PROM for LTCs. On the basis of previously published interviews with stakeholders, literature reviews, and indepth qualitative interviews, a conceptual framework was developed and refined. This framework served to develop 23 items to form the first draft of the new PROM. These items will be pretested in cognitive interviews to make any necessary amendments to ensure its relevance and validity before the new PROM - the LTCQ - is administered to a larger sample of people with LTCs in a survey to test its psychometric properties.

\section{Acknowledgments}

We would like to thank the participants with long-term conditions for taking part in this study, the CRN (Clinical Research Network) for supporting the recruitment of primary care practices, and the primary care practice staff for supporting the recruitment of people with long-term conditions. Furthermore, we would like to acknowledge the panel of experts who helped select the ten long-term conditions, and Dr Helen Lloyd and Dr Joanne Lloyd for conducting the schizophrenia interviews. This work was funded by the Policy Research Programme (PRP) in the Department of Health and by the National Institute for Health Research (NIHR). PRP funds the Policy Research Unit in the Quality and Outcomes of Person-Centred Care (QORU), a collaboration involving researchers in health and social care from the universities of Kent and Oxford and the London School of
Economics (LSE). The NIHR funds the Oxford Collaboration for Leadership in Applied Health Research and Care (CLAHRC). The schizophrenia project was funded by the European Federation of Associations of Families with Mental Illness (EUFAMI).

\section{Author contributions}

RF, MP, CJ, AC, and JF conceived the study. CP, LK, and $\mathrm{CH}$ conducted and analyzed the qualitative interviews. $\mathrm{CA}$ developed and tested the search strategy for identifying eligible participants. MP led the writing of the manuscript, with the contribution of all other authors. All authors contributed toward data analysis, drafting and critically revising the paper, gave final approval of the version to be published, and agree to be accountable for all aspects of the work.

\section{Disclosure}

The authors report no conflicts of interest in this work. The views expressed in this paper are those of the authors, and not necessarily those of the National Health Service, the NIHR, or the Department of Health.

\section{References}

1. Appleby J, Devlin NJ. Getting the Most out of PROMs: Putting Health Outcomes at the Heart of NHS decision-making. London: King's Fund; 2010.

2. Black N. Patient reported outcome measures could help transform healthcare. BMJ. 2013;346:f167.

3. Turner RR, Quittner AL, Parasuraman BM, Kallich JD, Cleeland CS. Patient-reported outcomes: instrument development and selection issues. Value Health. 2007;10 Suppl 2:S86-S93.

4. Rothman ML, Beltran P, Cappelleri JC, Lipscomb J, Teschendorf B. Patient-reported outcomes: conceptual issues. Value Health. 2007;10 Suppl 2:S66-S75.

5. US Food and Drug Administration. Guidance for Industry: PatientReported Outcome Measures: Use in Medical Product Development to Support Labeling Claims. Silver Spring (MD): FDA; 2009.

6. Pearson W, Bhat-Schelbert K, Probst J. Multiple chronic conditions and the aging of America: a challenge for primary care physicians. J Prim Care Community Health. 2012;3(1):51-56.

7. Barnett K, Mercer SW, Norbury M, Watt G, Wyke S, Guthrie B. Epidemiology of multimorbidity and implications for health care, research, and medical education: a cross-sectional study. Lancet. 2012;380(9836): $37-43$.

8. Moth G, Vestergaard M, Vedsted P. Chronic care management in Danish general practice: a cross-sectional study of workload and multimorbidity. BMC Fam Pract. 2012;13:52.

9. Anderson G, Horvath J. The growing burden of chronic disease in America. Public Health Rep. 2004;119:263-270.

10. Fortin M, Lapointe L, Hudon C, Vanasse A, Ntetu A, Maltais D. Multimorbidity and quality of life in primary care: a systematic review. Health Qual Life Outcomes. 2004;2:51.

11. UK Department of Health. The NHS Outcomes Framework 2013/14. London: MH; 2012.

12. UK Department of Health. The Adult Social Care Framework 2014/15. London: MH; 2013.

13. McGrail K, Bryan S, Davis J. Let's all go to the PROM: the case for routine patient-reported outcome measurement in Canadian healthcare. Healthc Pap. 2012;11(4):8-13. 
14. Hjollund NH, Larsen LP, Biering K, Johnsen SP, Riiskjaer E, Schougaard LM. Use of patient-reported outcome (PRO) measures at group and patient levels: experiences from the generic integrated PRO System, WestChronic. Interact J Med Res. 2014;3(1):e5.

15. Peters M, Crocker H, Jenkinson C, Doll H, Fitzpatrick R. The routine collection of patient-reported outcome measures (PROMs) for longterm conditions in primary care: a cohort survey. BMJ Open. 2014; 4(2):e003968.

16. Peters M, Crocker H, Dummett S, et al. Pilot Study of Patient Reported Outcome Measures (PROMs) in Primary Care. Oxford: University of Oxford; 2013.

17. Mujica-Mota RE, Roberts M, Abel G, et al. Common patterns of morbidity and multi-morbidity and their impact on health-related quality of life: evidence from a national survey. Qual Life Res. 2015;24(4):909-918.

18. Hunter C, Fitzpatrick R, Jenkinson C, et al. Perspectives from health social care and policy stakeholders on the value of a single self-report outcome measure across long-term conditions: a qualitative study. $B M J$ Open. 2015;5(5):e006986.

19. Murray CJL, Vos T, Lozano R, et al. Disability-adjusted life years (DALYs) for 291 diseases and injuries in 21 regions, 1990-2010: a systematic analysis for the Global Burden of Disease Study 2010. Lancet. 2012;380(9859):2197-2223.

20. Lloyd H, Lloyd J, Fitzpatrick R, Peters M. Outcomes that matter to people with schizophrenia: an in-depth study. Submitted. 2015.

21. UK Department of Health. The 2013/14 Adult Social Care Outcomes Framework. London: DH; 2012.

22. UK Department of Health. The NHS Outcomes Framework 2014/15. London: DH; 2013.
23. Ritchie J, Spencer L. Qualitative data analysis for applied policy research. In: Bryman A, Burgess R, editors. Analysing Qualitative Data. Abingdon, UK: Routledge; 1994.

24. Kerr C, Nixon A, Wild D. Assessing and demonstrating data saturation in qualitative inquiry supporting patient-reported outcomes research. Expert Rev Pharmacoecon Outcomes Res. 2010;10(3): 269-281.

25. Brod M, Tesler LE, Christensen TL. Qualitative research and content validity: developing best practices based on science and experience. Qual Life Res. 2009;18(9):1263-1278.

26. Fitzpatrick R, Davey C, Buxton M, Jones D. Evaluating patient-based outcome measures for use in clinical trials. Health Technol Assess. 1998;2(14):1-74.

27. Schuurmans H, Steverink N, Frieswijk N, Buunk BP, Slaets JP, Lindenberg S. How to measure self-management abilities in older people by self-report: the development of the SMAS-30. Qual Life Res. 2005;14(10):2215-2228.

28. McAllister M, Dunn G, Payne K, Davies L, Todd C. Patient empowerment: the need to consider it as a measurable patient-reported outcome for chronic conditions. BMC Health Serv Res. 2012;12:157.

29. Eton DT, Ridgeway JL, Egginton JS, et al. Finalizing a measurement framework for the burden of treatment in complex patients with chronic conditions. Patient Relat Outcome Meas. 2015;6: 117-126.

30. Malley J, Towers AM, Netten A, Brazier J, Forder J, Flynn T. An assessment of the construct validity of the ASCOT measure of social carerelated quality of life with older people. Health Qual Life Outcomes. 2012;10:21. 


\section{Supplementary material}

Table SI LTCQ interview participants

\begin{tabular}{|c|c|c|c|c|}
\hline Sex & Age, years & Ethnicity & LTCs & Social care \\
\hline Male & 69 & White British & Cancer - lymphoma & Did not report using social care \\
\hline Male & 71 & White British & $\begin{array}{l}\text { Diabetes type } 2 \text {, cancer - chronic lymphatic } \\
\text { leukemia }\end{array}$ & Did not report using social care \\
\hline Female & 80 & White British & OA, hypothyroidism, and hiatus hernia & Uses day center \\
\hline Male & 88 & White British & Diabetes, COPD, OA, and hypertension & Did not report using social care \\
\hline Male & 87 & White British & Cancer and chronic skin condition & In private care home \\
\hline Female & 54 & White British & Multiple sclerosis & Did not report using social care \\
\hline Male & 69 & White British & Stroke/TIA and epilepsy & Did not report using social care \\
\hline Female & 70 & White Irish & Diabetes and thyroid condition & Did not report using social care \\
\hline Female & 44 & White British & Depression and OA & Did not report using social care \\
\hline Female & 97 & White British & $\begin{array}{l}\text { OA, hypertension, hearing loss, chronic } \\
\text { back pain, knee replacement, and sciatica }\end{array}$ & In private care home \\
\hline Male & 59 & White British & Diabetes type 2 & Did not report using social care \\
\hline Female & 76 & White British & COPD, asthma, OA, and diverticulitis & Did not report using social care \\
\hline Female & 66 & White European & MS & Did not report using social care \\
\hline Male & 35 & White British & IBD and chronic renal failure & Did not report using social care \\
\hline Female & 33 & Egyptian & IBD - ulcerative colitis & Did not report using social care \\
\hline Female & 64 & White British & $\begin{array}{l}\text { MS (possibly polio secondary effects), arthritis, stroke, } \\
\text { and vision problems }\end{array}$ & Son as carer \\
\hline Male & 75 & South Asian & IHD (angina, stent) & Did not report using social care \\
\hline Female & 58 & South Asian & Diabetes, heart failure, and chronic kidney disease & Did not report using social care \\
\hline Male & 80 & South Asian & Diabetes type 2 and IHD & Did not report using social care \\
\hline Female & 49 & White British & $\begin{array}{l}\text { Diabetes type 2, borderline personality disorder, and } \\
\text { sciatica }\end{array}$ & Yes, she cares for daughter \\
\hline Male & 51 & White British & Crohn's (IBD) & Did not report using social care \\
\hline Male & 61 & White British & MS & Did not report using social care \\
\hline Male & 70 & White British & $\begin{array}{l}\text { Diabetes, OA, stroke, angina, } \\
\text { hypertension, and cancer }\end{array}$ & Did not report using social care \\
\hline Male & 65 & White British & Diabetes type 2 & Did not report using social care \\
\hline Female & 55 & White British & MS & Receives benefits \\
\hline Male & 70 & White British & $\begin{array}{l}\text { Diabetes type } 2 \text {, stroke, IHD (angina), } \\
\text { gout, and chronic back pain }\end{array}$ & Did not report using social care \\
\hline Male & 72 & White British & $\begin{array}{l}\text { Arthritis, asthma, diabetes, and } \\
\text { polio-related issues }\end{array}$ & Did not report using social care \\
\hline Male & 77 & White British & IHD (heart attack, angina) & Did not report using social care \\
\hline Male & 67 & White British & MS & Did not report using social care \\
\hline Female & 64 & White British & $\begin{array}{l}\text { COPD, stroke, arthritis, agoraphobia, depression, IHD } \\
\text { (atrial fibrillation), gout, } \\
\text { and stenosis of spine }\end{array}$ & Did not report using social care \\
\hline Female & 58 & $\begin{array}{l}\text { Not confirmed - on } \\
\text { phone }\end{array}$ & Diabetes type I and asthma & Did not report using social care \\
\hline Female & 66 & White British & IBD (ulcerative colitis) and cancer & Did not report using social care \\
\hline Male & 69 & White British & IHD (angina, triple bypass) & Did not report using social care \\
\hline Female & 65 & White & MS & Did not report using social care \\
\hline Female & 43 & White & Bipolar disorder & Day center \\
\hline Male & 59 & White British & Diabetes, arthritis, and circulatory problems & Did not report using social care \\
\hline Female & 68 & South Asian & Diabetes type 2 and arthritis - psoriatic & Did not report using social care \\
\hline Male & 59 & White British & Neurofibromatosis type I and dyslexia & Did not report using social care \\
\hline Female & 45 & White British & MS & Did not report using social care \\
\hline Female & 69 & White British & MS & Did not report using social care \\
\hline Male & 30 & Not confirmed & MS & Did not report using social care \\
\hline Male & 31 & White British & Depression and drug-induced psychosis & Did not report using social care \\
\hline
\end{tabular}




\begin{tabular}{|c|c|c|c|c|}
\hline Sex & Age & Ethnicity & LTCs & Social care \\
\hline \multicolumn{5}{|c|}{ Schizophrenia study participants } \\
\hline Male & 45 & White British & $\begin{array}{l}\text { Paranoid schizophrenia, anxiety, depression, and spinal } \\
\text { stenosis }\end{array}$ & Did not report using social care \\
\hline Female & 29 & Black British & Paranoid schizophrenia and depression & Did not report using social care \\
\hline Female & 58 & White European & $\begin{array}{l}\text { Paranoid schizophrenia, breast cancer, and long-term } \\
\text { hepatitis C }\end{array}$ & Did not report using social care \\
\hline Male & 36 & White British & Schizophrenia (paranoid psychosis) & Did not report using social care \\
\hline Male & 60 & White British & Paranoid schizophrenia & Did not report using social care \\
\hline Male & $30 s$ & White British & Schizophrenia & Did not report using social care \\
\hline
\end{tabular}

Abbreviations: LTC, long-term condition; LTCQ, Long-Term Conditions Questionnaire; COPD, chronic obstructive pulmonary disease; TIA, transient ischemic attack; IBD, inflammatory bowel disease; IHD, ischemic heart disease; MS, multiple sclerosis; OA, osteoarthritis.

\section{Publish your work in this journal}

Patient Related Outcome Measures is an international, peer-reviewed, open access journal focusing on treatment outcomes specifically relevant to patients. All aspects of patient care are addressed within the journal and practitioners from all disciplines are invited to submit their work as well as healthcare researchers and patient support groups.
The journal is included in PubMed. The manuscript management system is completely online and includes a very quick and fair peer-review system. Visit http://www.dovepress.com/testimonials.php to read real quotes from published authors.

Submit your manuscript here: http://www.dovepress.com/patient-related-outcome-measures-journal 